\title{
Design and Delivery of Technical Module for the Business Intelligence Course
}

\author{
Shouhong Wang \\ University of Massachusetts, \\ Dartmouth, MA, USA
}

swang@umassd.edu

\author{
Hai Wang \\ Saint Mary's University, \\ Halifax, NS, Canada
}

hwang@smu.ca

\section{Executive Summary}

IS programs are increasingly being called on to offer courses in business intelligence. This article presents the pedagogical design and the delivery method of a practicable technical module for a nontechnically oriented Business Intelligence course. It is a tutorial for the instructors who wish to incorporate a practical technical element in their business-oriented Business Intelligence courses. The subject of the technical module discussed in this article is OLAP (Online Analytical Process). OLAP is the most commonly used technique of business intelligence but tends to be underemphasized in the existing textbooks and the pedagogy literature. The technical module of our Business Intelligence course covers four important parts: (1) a framework of OLAP strategy for business intelligence; (2) a guideline of OLAP practices in the Microsoft Office environment; (3) a set of elemental OLAP techniques including query, OLAP cube operations, statistical analysis, and data visualization; and (4) a technical assignment of OLAP. Our preliminary student feedback has indicated the usefulness of this technical module.

Keywords: Business intelligence, OLAP, course design, tutorial.

\section{Introduction}

IS educators are developing new IS courses to meet the needs of the IT job market (Helfert, 2008; Houghton \& Ruth, 2010; Hunter, 2010; Tan \& Venables, 2008; Topi et al., 2010). Business Intelligence (BI) is one of the emerging topics (Jafar, 2010; Presthus \& Bygstad, 2012). In its broadest definition, BI is a conceptual framework for decision support. It combines IS architecture, databases, analytical tools, and applications (Raisinghani, 2004). Given the breadth of the topic, it is natural that there are a variety of approaches to the pedagogical design of this course. Generally, the design of the BI course can be placed in two major categories: non-technical and technical.

In a non-technical BI course, students study BI cases (e.g., Howson, 2008; Laursen \& Thorlund 2010; Loshin, 2003; Williams \& Williams, 2007). Students in these courses typically learn the value of BI

Material published as part of this journal, either on-line or in print, is copyrighted by the Informing Science Institute. Permission to make digital or paper copy of part or all of these works for personal or classroom use is granted without fee provided that the copies are not made or distributed for profit or commercial advantage AND that copies 1) bear this notice in full and 2) give the full citation on the first page. It is permissible to abstract these works so long as credit is given. To copy in all other cases or to republish or to post on a server or to redistribute to lists requires specific permission and payment of a fee. Contact Publisher@InformingScience.org to request redistribution permission. for business and receive a non-technical overview of a variety of BI techniques such as OLAP (online analytical process), data mining, text mining, and others. In this approach, students learn that BI has created great opportunities for organizations to utilize massive data to support decision making. Students acquire a general concept of BI techniques, but are not required to perform technical exercises or to conduct technical projects. On the other hand, in a tech- 
nical BI course, students are expected to master the implementation and application of the various technologies supporting BI (Shmueli, Patel, \& Bruce, 2007).

Given the restricted number of elective courses in the IS curricula, it is ideal to have a single integrated BI course that integrates the two approaches. However, the textbooks to meet this demand are scarce. In our experience, Turban, Sharda, Delen, and King's (2011) textbook is the only widely circulated textbook that is suitable for a single business-oriented BI course with adequate non-technical and technical modules. The non-technical module of Turban et al.'s textbook covers the major concept of BI and business cases of BI applications. The technical module includes online access to data mining tools and BI software. The technical module allows students to practice data mining with neural networks, text mining, and statistical analysis.

When using Turban et al.'s (2011) textbook, we found that the advanced data mining techniques, such as neural networks and text mining, were too sophisticated for business students to understand even though students have already been introduced to statistical analysis used in BI in their required business statistics course. OLAP is underemphasized in the Turban et al.'s textbook, and hands-on material of OLAP is completely absent there. In fact, few available textbooks offer the OLAP hands-on material that goes beyond a concise introduction. Although a number of BI pedagogical papers (Mrdalj, 2007; Negash, 2004) provide overviews of BI courses, the pedagogical design and teaching material of OLAP for an integrated BI course are virtually missing in the IT education literature. Due to the widespread reliance on OLAP in BI, its absence in typical IS BI course designs appears to represent a serious shortcoming (Howson, 2012). Hence, the development of a practicable technical module of OLAP for the integrated BI course is imperative. This article describes the design and the delivery of a technical module of OLAP for our BI course in detail. Indeed, this article is a tutorial for the instructors who wish to incorporate a practical technical module in their business-oriented BI courses. The rest of the article is organized as follows. The next section describes the design of a framework of OLAP strategy. The third section explains the Microsoft Office environment for OLAP. The fourth section illustrates the elemental OLAP techniques. The fifth section describes our experience teaching the OLAP module, and the final section summarizes this tutorial.

\section{Design of Framework of OLAP Strategy}

An OLAP tool is typically available in almost every major BI suite system on the software market (Howson, 2012). The OLAP techniques not only lays a foundation for students to learn other BI approaches (e.g., data mining using artificial intelligence), but also helps students develop a better understanding of the general concept of BI. The technical module discussed in this article starts with a framework of OLAP strategy for BI.

A key point that students must learn is that data and the BI tools, including OLAP, do not generate meaningful knowledge automatically. Users require a priori knowledge of the business context and pertinent objectives of the analytical process to successfully employ BI. As a given data set can be viewed from many standpoints, an effective BI analysis must meet a clear business objective (Olszak $\&$ Ziemba, 2012). Therefore, the first subject of OLAP is a user-centric framework of BI strategy development. First, in order to effectively employ OLAP, the user must be a business insider who understands the specific context of business. The business users should have hypotheses about the type of information likely to be useful and how it might be employed in decision-making. Second, as there are virtually infinite ways to conduct OLAP, users' objectives for the specific analysis should be established prior to conducting OLAP. Third, as the data available for OLAP could be extremely large, it is crucial for the user to select a set of limited data and optimize the utility of the data set for the proposed OLAP analysis. Finally, as there are a variety of OLAP techniques, consideration should be given to the selection of techniques appropriate to the study objectives and the skills of the individuals who will be conducting the analysis. The emphasis of the technical module presented 
below is to provide students with basic skills so they can participate in choosing appropriate techniques. Overall, OLAP is not a one-shot operation, but is a trial-and-error process.

To assist students to learn the conceptual framework, we have created a diagram that highlights the aspects of OLAP strategy development as illustrated in Figure 1.
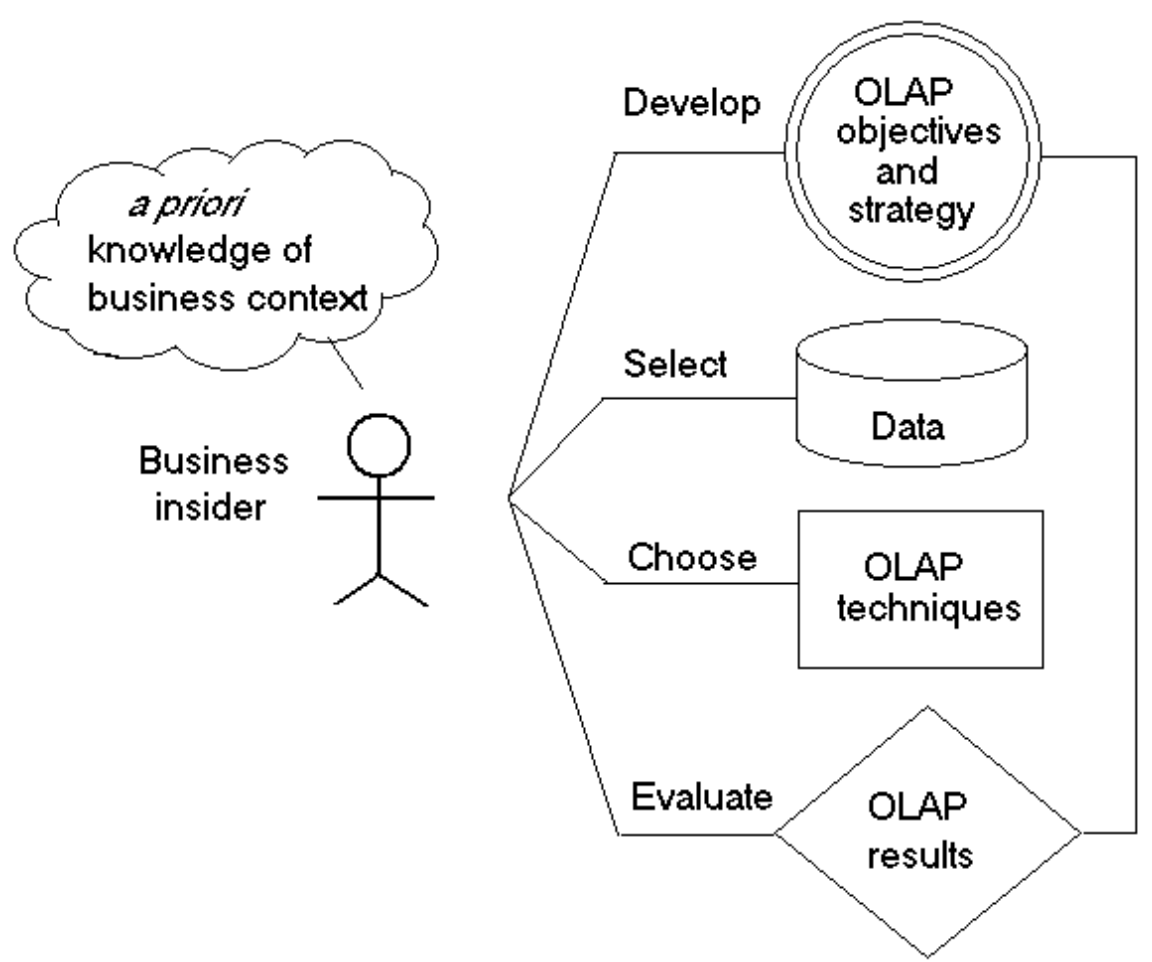

Figure 1. User-Centric Framework of OLAP Strategy Development

Generally, an OLAP strategy is a set of generalized or coarse hypotheses in the user's mind that OLAP processes are used to verify or disprove. Clearly, an OLAP strategy highly depends upon the business context, and there is no single formula for setting up the OLAP strategies. Nevertheless, we provide a set of common guidelines for the OLAP strategy development, as listed below.

- Focus on the critical factors of the business, potential problems and possible opportunities;

- Focus on the key performance indicators;

- Find correlations or associations among data relating to critical factors and key indicators;

- Find exceptional facts;

- Detect abnormal observations;

- Detect time-dependent trends, short-term, medium-term, and long-term;

- Verify or disprove the outcome of a business decision or a business action; and

- Verify or disprove a novel idea.

\section{Design of Computational Environment of OLAP}

\section{Microsoft Office Environment for OLAP}

The second subject of the technical module is the computational environment of OLAP. Given the trial-and-error nature of OLAP, OLAP heavily relies on the human-computer interaction. Hence, us- 
er-computer interface is an important factor in OLAP. Many users are passionate about the features of spreadsheet integration in Microsoft Excel, leading to Microsoft Office becoming a widely-used BI tool (King, 2009). Many leading OLAP products, such as SAP Duet and SAS, use Excel as their user-computer interface. Microsoft Excel itself has essential OLAP functions to meet the challenge of BI. Microsoft Office is available at almost every educational institution as a necessary computing tool for business students and, thus, is an ideal computational environment for us.

This section explains the Microsoft environment supporting OLAP and introduces key OLAP concepts. Microsoft Office includes Microsoft Access, an end-user oriented database management system. Microsoft Access is connected to Microsoft Excel through the internal database connection. One can input data in the Access database form to Excel without setting ODBC (Open Database Connectivity), and the operation of data input from Access to Excel is seamless. More importantly, Excel and Access use a common form of database queries which is a part of OLAP. In our OLAP environment setting, Access database is employed to explain the data source input, but the knowledge of relational database is not a prerequisite of this technical module for students.

We have created a diagram to display the components of Microsoft Office OLAP environment to students, as shown in Figure 2. The non-shaded parts in Figure 2 are relevant to the present context of OLAP hands-on practice; that is, data cube of Access database, Excel pivot table, Microsoft Query, common spreadsheet functions, data presentation chart, and data statistical analysis tools are the major components of the technical module.

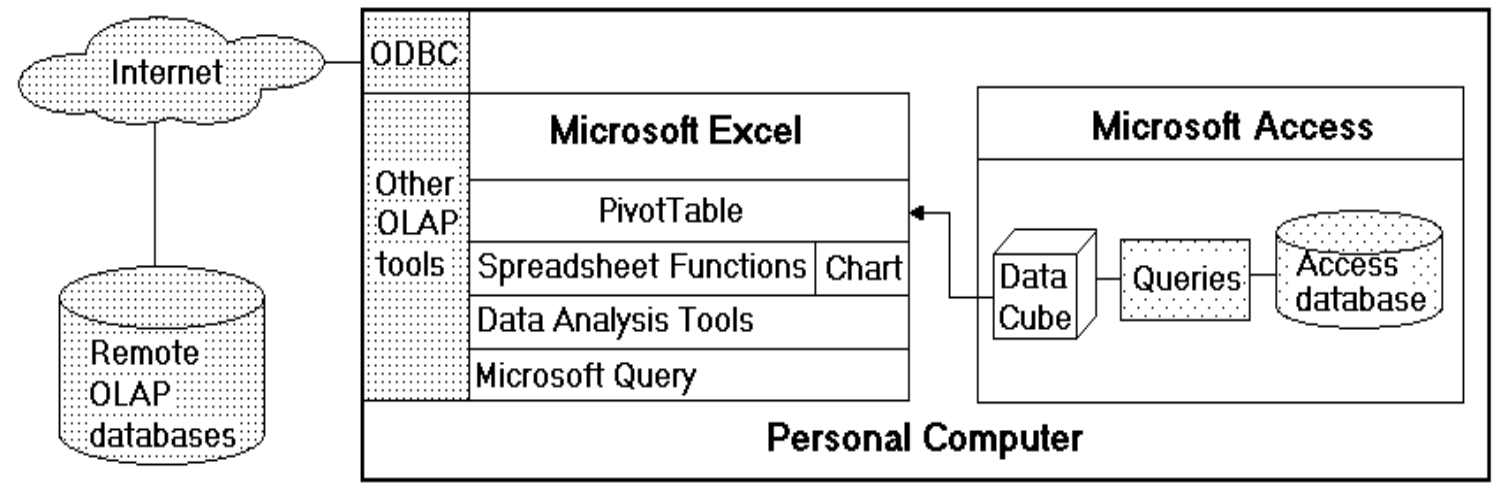

Figure 2. Microsoft Office Environment for OLAP

\section{Data Cube for OLAP in Microsoft Office}

Typically, the data used for OLAP is a high-dimensional data set which describes the facts with various attributes such as what, who, where, when, how, etc. A high-dimensional data set is called a data cube. The data cube used for OLAP is also called OLAP cube. The entity-relationship diagram shown in Figure 3 describes a data cube. This style of entity-relationship diagram for data cube is called star schema because there is the fact table (i.e., the data cube) in the center surrounded by several dimension tables. The three-dimension data cube actualized with data is illustrated in Figure 4. A data cube can be generated directly in Microsoft Access through a query, and can then be imported into Excel for OLAP. For students to practice OLAP in Excel, a small sample data set as illustrated in Figure 4 was created in the Microsoft Access form. 


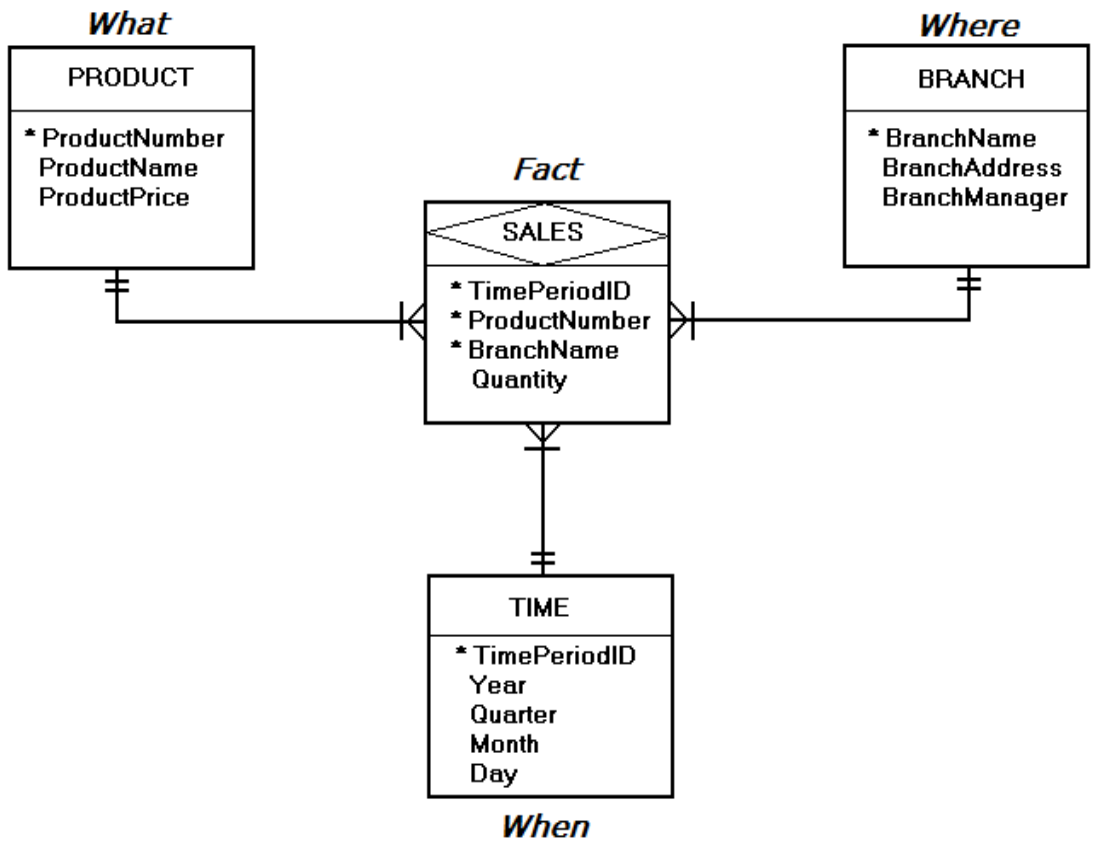

Figure 3. Sample Star Schema for Data Cube

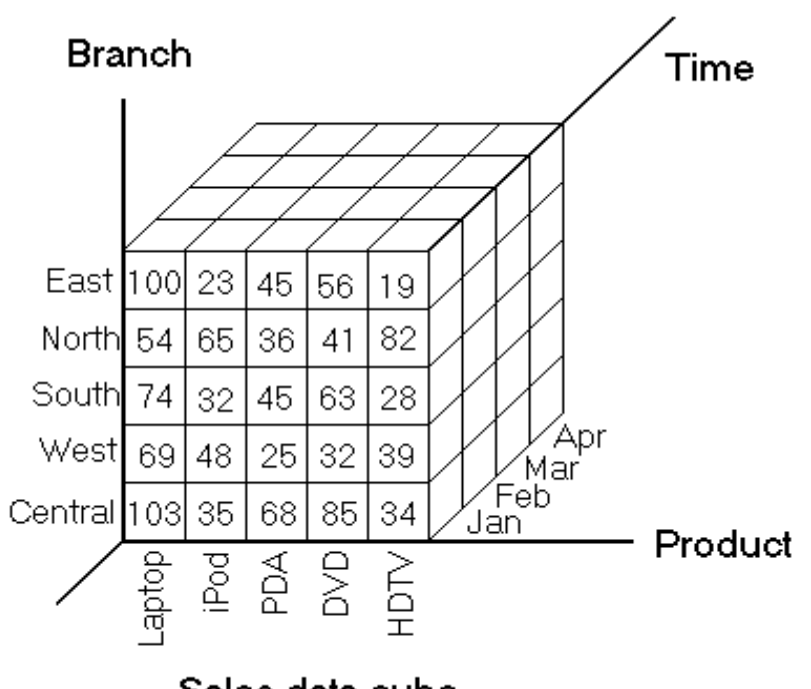

Figure 4. Data Cube with High-Dimensional Data

A data cube is stored in the database as a two-dimensional table that arranges the high-dimensional data in a certain way. Because human brains have difficulties in processing high-dimensional data by using a flat two-dimensional table, OLAP tools employ pivot tables to represent high-dimensional data. A pivot table is a set of two-dimensional tables that are recursively embedded at each level of each of the dimensions, as illustrated in Figure 5. As shown in Figure 5, the Sales related to Time and Product can be represented by a two-dimensional table that has the Time dimension for the rows and the Product dimension for the column. For the additional dimension of Branch, two-dimensional tables with Time and Product are generated at each branch, and a larger two-dimensional table with the 
Branch dimension for the column is created. The larger table is the pivot table representing the Time, Product, and Branch dimensions. The large two-dimensional pivot table embeds the smaller twodimensional table for each branch. If there is an additional dimension (say, Chanel (how)), an additional pivot table can be generated for each level of Chanel (e.g., Online, Mailing, Phone, Store), and an even larger pivot table can be created to represent the four dimensions.

\begin{tabular}{|c|c|c|c|c|c|c|}
\hline \multicolumn{7}{|c|}{ Sales } \\
\hline \multirow[b]{2}{*}{ Branch } & \multirow[b]{2}{*}{ Time } & \multicolumn{5}{|c|}{ Product } \\
\hline & & Laptop & iPod & PDA & DVD & HDTV \\
\hline \multirow[t]{4}{*}{ East } & Jan & 100 & 23 & 45 & 56 & 19 \\
\hline & Feb & 74 & 53 & 33 & 24 & 31 \\
\hline & Mar & 28 & 38 & 26 & 54 & 29 \\
\hline & Apr & 76 & 74 & 34 & 32 & 53 \\
\hline \multicolumn{2}{|l|}{ East Total } & 278 & 188 & 138 & 166 & 132 \\
\hline \multirow[t]{4}{*}{ West } & Jan & 69 & 48 & 25 & 32 & 39 \\
\hline & Fab & 49 & 23 & 43 & 26 & 38 \\
\hline & Mar & 66 & 45 & 78 & 86 & 74 \\
\hline & $\mathrm{Apr}$ & 63 & 13 & 15 & 47 & 23 \\
\hline \multicolumn{2}{|l|}{ West Total } & 247 & 129 & 161 & 191 & 174 \\
\hline North & \begin{tabular}{|l|}
$\operatorname{Jan}$ \\
\end{tabular} & 54 & $6 \underline{5}$ & 36 & 41 & 82 \\
\hline
\end{tabular}

Figure 5. Pivot Table for a Data Cube

To conduct OLAP in Microsoft Office, one must create a pivot table in Excel that imports the data cube from a database. Access database is used for this technical module for simplicity. Suppose the data cube has been generated and is stored in an Access database as a database table. Start Excel, click on [Insert] on the ribbon, and then click on [PivotTable], the Create Pivot Table pane will show up. Choose [Use an external data source], click on the [Choose Connection] button, and the Existing Connection pane will show up. Click on the [Browse for More...] button, find the Access database for downloading, and click on [Open] to connect the database. After connecting to the database, the data cube table in Access can be selected in the Select Table pane, and can be imported in the Create Pivot Table pane. Finally, the PivotTable Tools window allows the user to make the pivot table ready for OLAP.

Clearly, a database can contain many data cubes. As discussed in the second section, the selection of a data cube for an OLAP practice depends on the OLAP strategy. The selected data cube for the OLAP task is the OLAP cube. Figure 6 shows the pivot table of a sample OLAP cube that is included in the technical module for students to practice simple OLAP tasks, as discussed in the next section. 


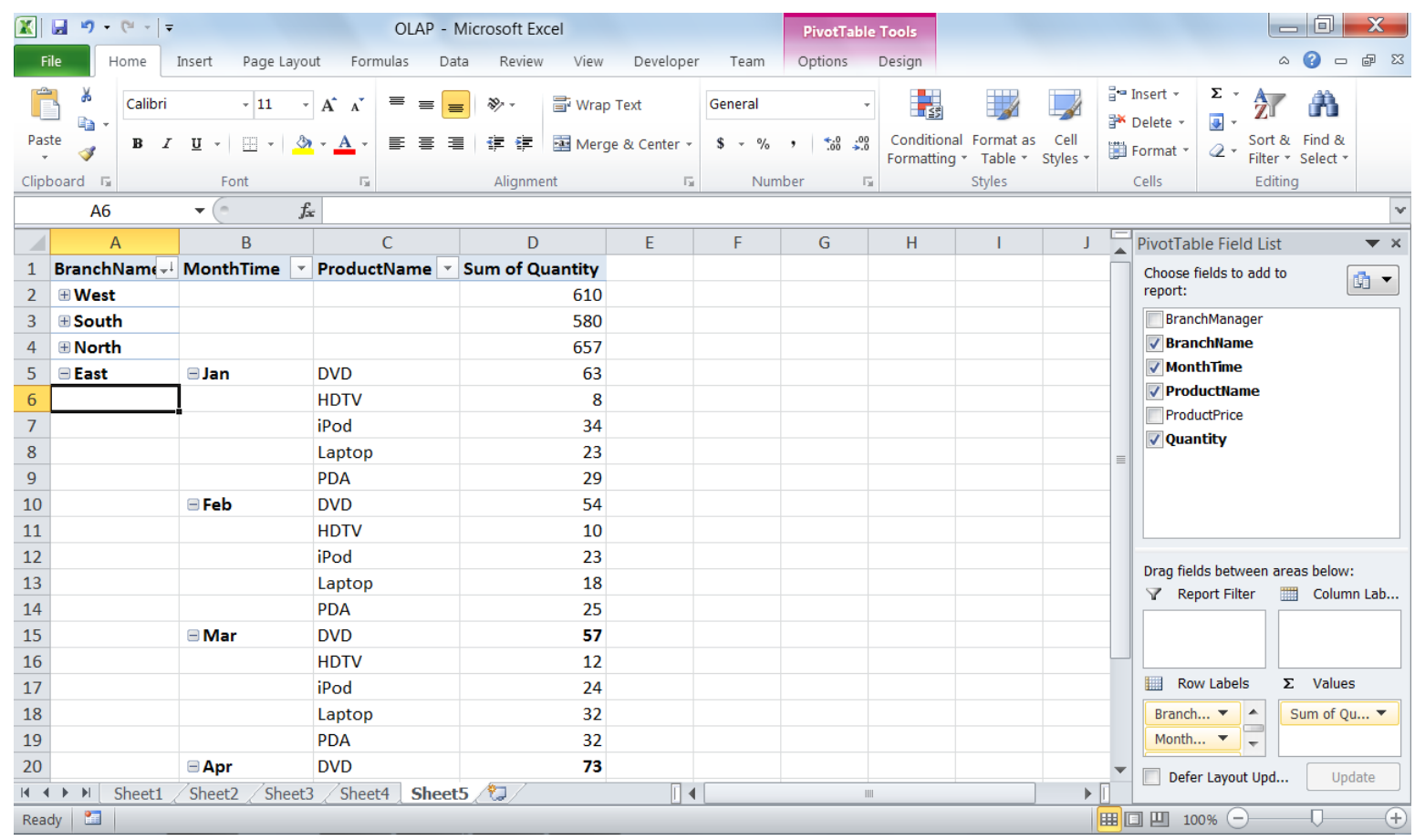

Figure 6. Pivot Table in Excel Implements OLAP Cube

\section{Design of Elemental OLAP Techniques}

Given the OLAP cube, one can use a variety of techniques to find interesting facts that meet the OLAP objectives. The next subject of the technical module is to introduce important OLAP techniques to students.

\section{Elemental OLAP Techniques}

An OLAP task can be accomplished by moving through different paths and by using various techniques. It is important for students to learn the elemental techniques of OLAP. An elemental OLAP technique is a basic technique of OLAP that can be combined with other elemental OLAP techniques to become a more sophisticated OLAP method. Four elemental techniques of OLAP have been identified for the technical module. They are query, OLAP cube operation, statistical analysis, and data visualization. A complex OLAP task can be accomplished by using a combination of these elemental techniques. To help students learn these elemental techniques, this section includes an OLAP prototype for each of the four elemental techniques. An OLAP prototype of an elemental technique is a template of basic OLAP tasks that can be accomplished by applying the elemental technique to the sample OLAP cube shown in Figure 6. An OLAP prototype is concise and can be practiced and imitated by students to develop the OLAP skills. Next, the four elemental OLAP techniques and their prototypes are discussed.

\section{Query}

A query is a set of instructions for processing the data with any dimensionality to extract useful information. One can create queries using SQL or QBE (Query By Example) in Excel or in Access. Using queries, one can find needed facts from the OLAP cube though selecting the data and defining the query criteria. Simple functions of queries include select, sort, group, filter, etc. Sophisticated queries can provide information concerning correlations among data.

The basic OLAP task prototype for students to learn and practice query is: 
[Branch] has the highest sales of [Product] in [Time Period], in comparison with [Other Branches].

We provide detailed steps to use the Microsoft Query window in Excel for students to develop queries. Suppose the OLAP prototype is actualized to "find Laptop top selling months and the responsible branch." One may set the query criteria, such as "Product = 'Laptop' and SalesQuantity $>30$ ", in the Microsoft Query window to run the query on the selected data set, and the query will find the result similar to the one shown in Figure 7. The fact revealed by this simple OLAP task using the query elemental technique would be:

"East Branch had the highest sales of Laptop in both March and April, although other branches (West and Central) had the same sales levels in one of the two months."

This section sets three learning goals for students. First, students shall be able to use the query technique in Excel for OLAP. Second, students shall understand the types of basic OLAP tasks as articulated in the prototype that can be accomplished by queries. Third, students shall be able to extend the OLAP prototype to add conceivable meaningful facts. For example, a student might want to extend the OLAP prototype to find out the lowest sales of products in alternative months.

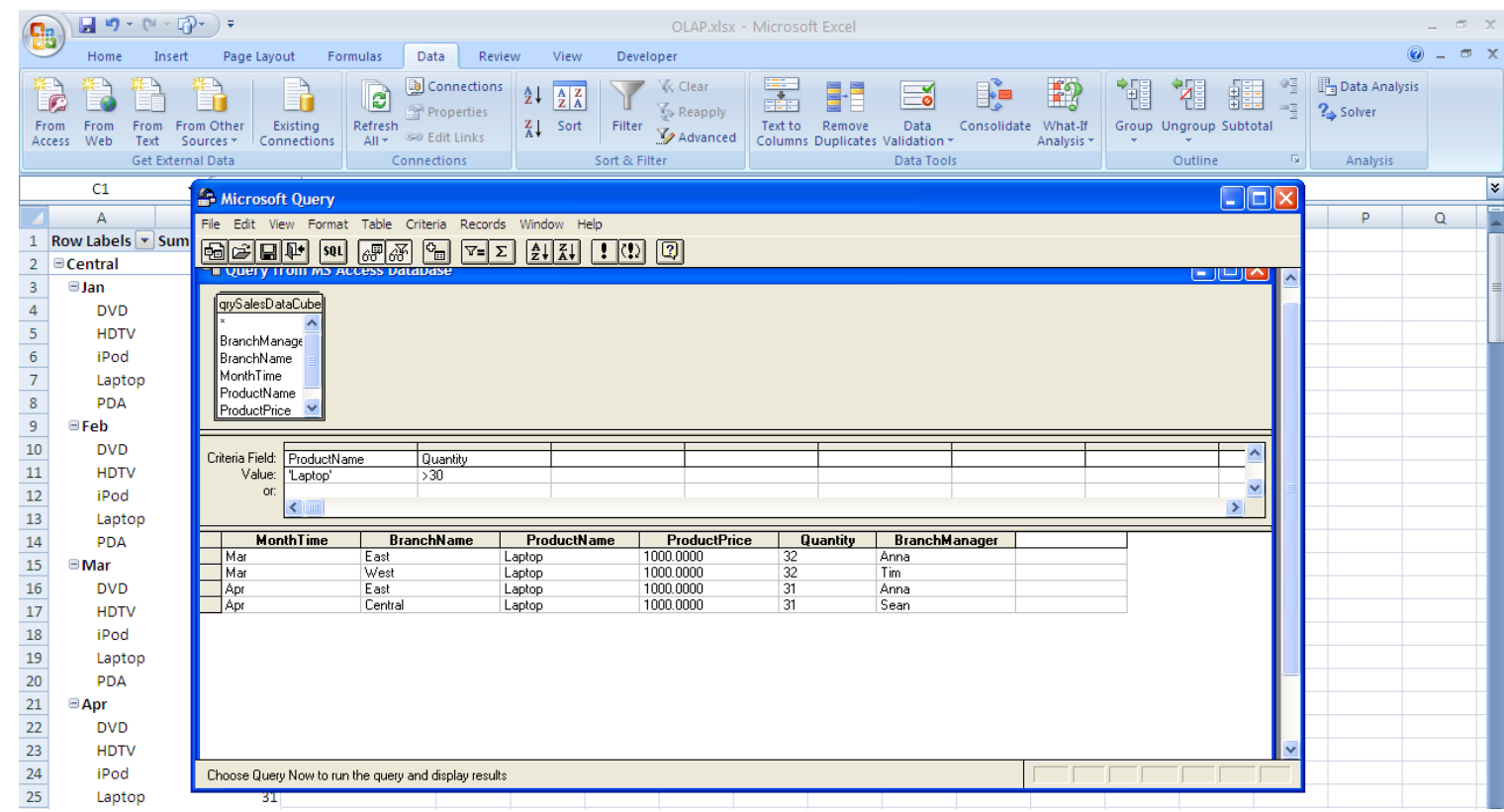

Figure 7. Query

\section{OLAP Cube Operations: Slicing, Dicing and Drill-down}

The OLAP cube can be manipulated to help reveal interesting facts and relationships in the data. This part discusses three techniques for manipulating an OLAP cube: slicing, dicing, and drill-down.

Slicing is to reduce the dimensionality of the OLAP cube by fixing the level(s) of one or more dimensions to create slices. Figure 8 illustrates slicing. 

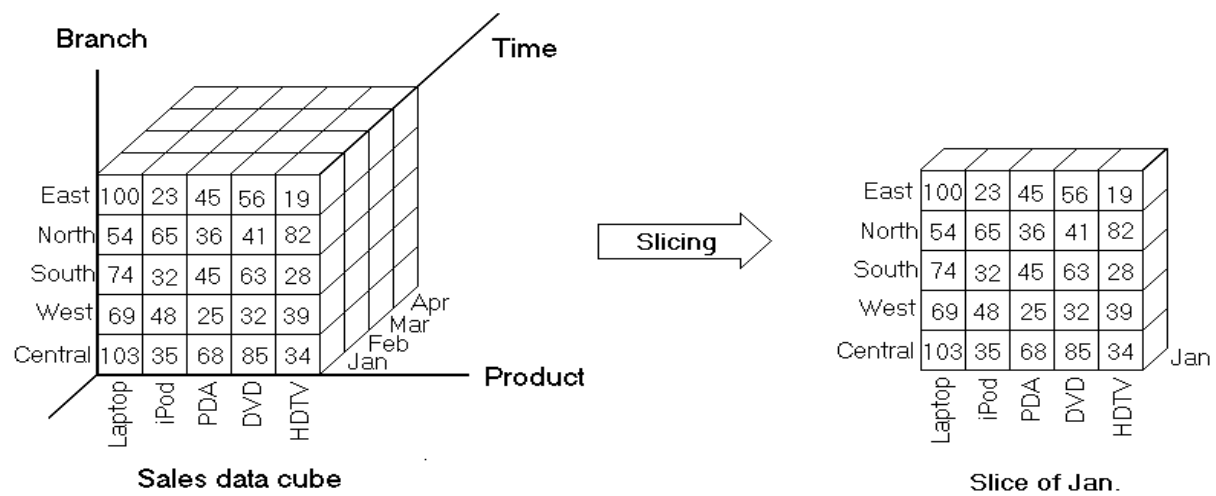

Figure 8. Slicing

Dicing is to divide the OLAP cube into sub-cubes (so called dice) for comparison. Figure 9 illustrates dicing.

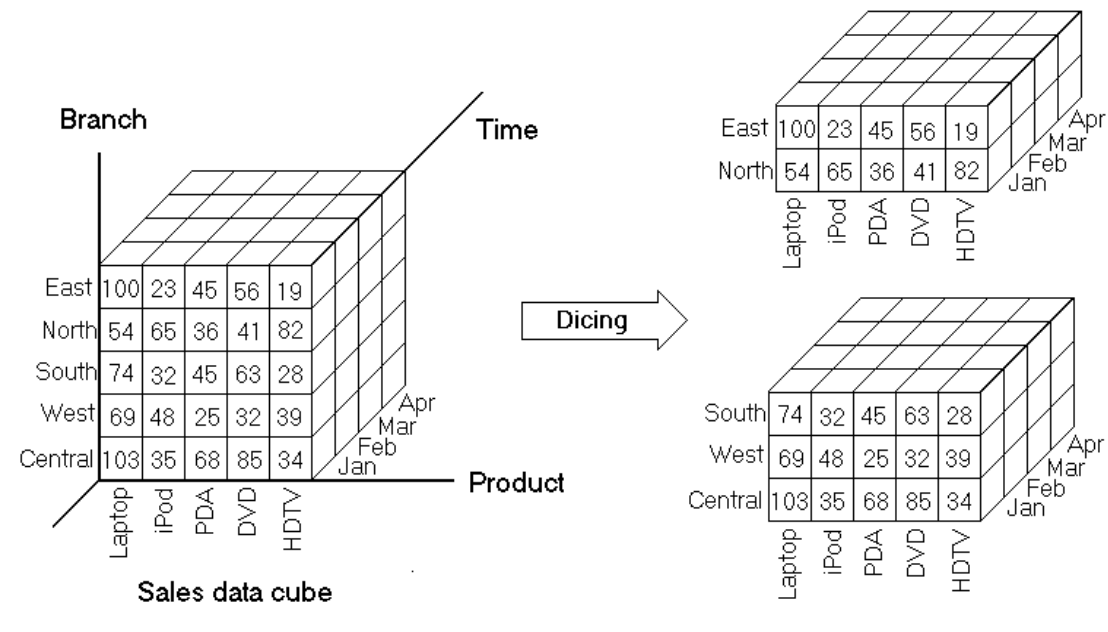

Two Dices

Figure 9. Dicing

The operations of slicing and dicing make the OLAP cube smaller to reveal detailed information. A pivot table can be used for slicing and dicing operations through the [PivotTable Tools] in Excel. The expand-collapse button (with the plus/minus sign) next to the item is used to expand (for the insertion to the slice/dice) or collapse (for the deletion from the slice/dice) the data item. Figure 10 shows an example of using the expand-collapse buttons to create a slice for Sales of East Branch in March and April.

A drill-down process is a combination of slicing and dicing with other techniques (such as queries and statistical analysis) to investigate information in increasing details. This part includes a basic OLAP task prototype for students to learn and practice OLAP cube operations and drill-down as follows.

[Branch] has significant increase of sales of [Product] in [Time Period] compared with [Time Period] by [Percentage]. 


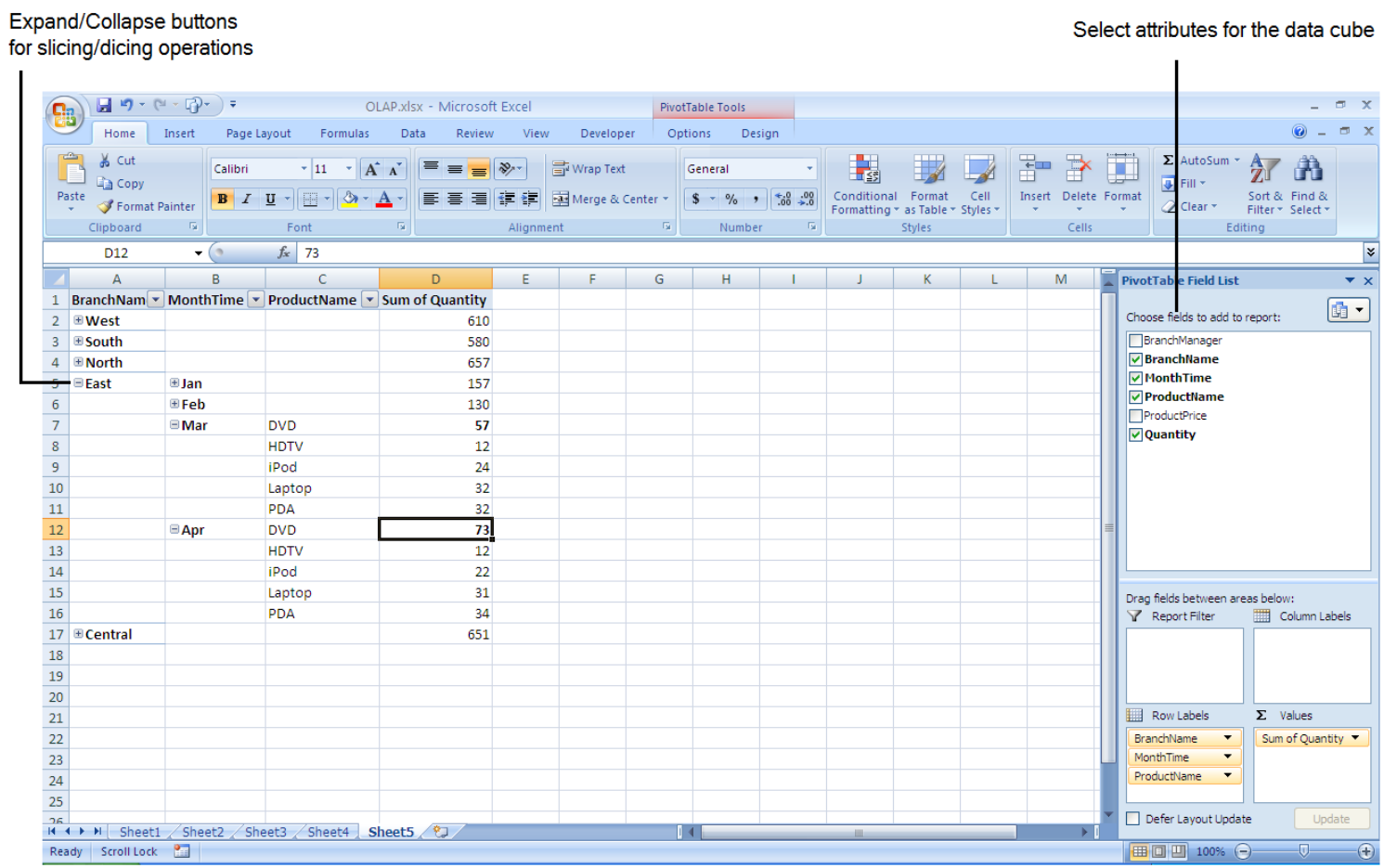

Figure 10. Slicing and Dicing in Pivot Table

One can apply the slicing and dicing operations to the data of the pivot table shown in Figure 10 and use a simple calculation to reveal such fact for this OLAP task as:

"East Branch has a significant increase of sales of DVD in April compared with March by 28\% ((7357)/57)."

This section sets three learning goals for students. First, students shall be able to perform slicing, dicing, and drill-down operations in Excel using a pivot table. Second, students shall understand the types of basic OLAP tasks as articulated in the prototype that can be accomplished by OLAP cube operations. Third, students shall be able to extend the OLAP prototype to add conceivable meaningful facts that can be revealed through OLAP cube operations.

\section{Statistical Analysis}

Excel has a package of common statistical analysis tools called Analysis ToolPak. Normally, one needs to active the statistical analysis tools by using [Add-in] in the [File]-[Options] menu so that [Data Analysis] will appear on the menu of [Data]. OLAP is supported by statistical analysis. Statistical analysis in Excel includes descriptive statistics (e.g., Sum, Min, Max, and Average), $t$ test, $z$-test, ANOVA, MANOVA, regression, etc. It is difficult to apply data analysis directly to the pivot table. One needs to take advantage of the copy-paste operation in Excel to copy the needed data set from the pivot table and to paste it to a separate sheet before applying the data analysis to the new table.

This section includes a basic OLAP task prototype for students to learn and practice statistical analysis as follows.

The difference of sales between [Branch A] and [Branch B] is statistically significant/insignificant given [Statistical Test]. 
An example of statistical analysis for OLAP is shown in Figure 11. The sales data of West Branch as well as South Branch are copied from the pivot table, and $t$-test is applied to the extracted data sets. The statistical analysis result reveals the information for this basic OLAP task would be:

"The difference of sales between West Branch and South Branch is insignificant, although the average sales of West Branch is slightly higher than sales of South Branch by 5\% ((30.5-29)/29)."

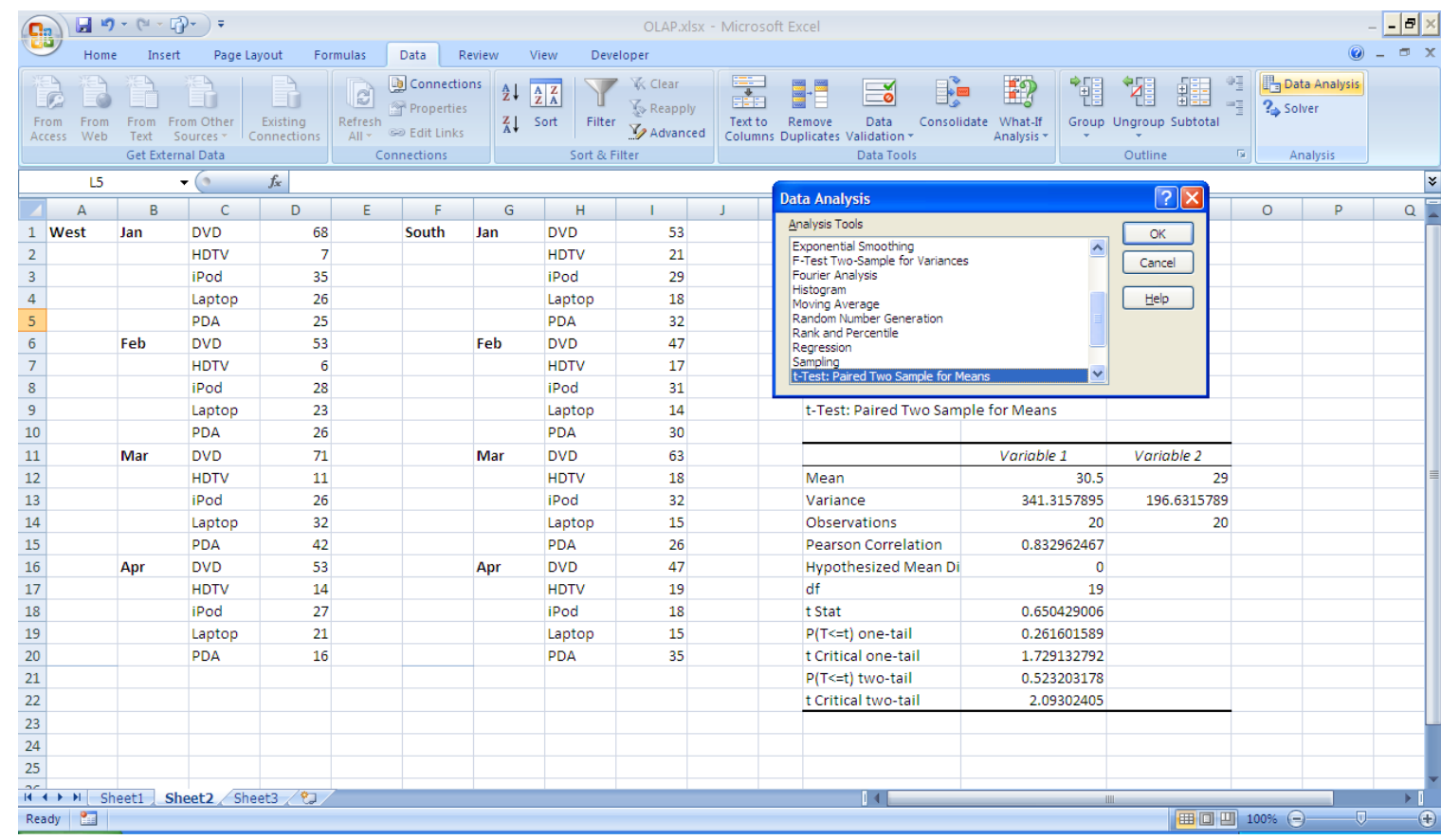

Figure 11. Statistical Analysis

This section sets three learning goals for students. First, students shall be able to use basic statistical analysis tools learned from the statistics course for OLAP. Second, students shall understand the types of basic OLAP tasks as articulated in the prototype that can be accomplished by statistical analysis. Third, students shall be able to extend the OLAP prototype to add more statistical analyses.

\section{Data Visualization}

Business graphics (line chart, bar chart, pie chart, etc.) are commonly used for data visualization to support human cognitive activities in analytical processing. The major purpose of the use of business graphics in OLAP is to effectively support comparison, trends tracing, pattern discovery, and exception detection. Excel has good data visualization functions with a variety of charts. This is one of the important features of Excel as the user-computer interface for OLAP. There is a PivotChart function in Excel. However, the ordinary Chart function is easier to use and understand.

This section includes a basic OLAP task prototype for students to learn and practice data visualization as follows.

The pattern of sales of [Product A] is similar/dissimilar to that of [Product B] during [Time Periods].

Given the sample OLAP cube, the data of sales of the four products over the past four months are copy-pated to a new data sheet. By using the Chart Tools functions, one can generate line charts to 
make a comparison of the sales of products over the time period, as shown in Figure 12. The data visualization result reveals the information for this basic OLAP task would be:

The sales of all products have the similar sales pattern over the past time periods. The contributions of each product to the sales seem to be stable.

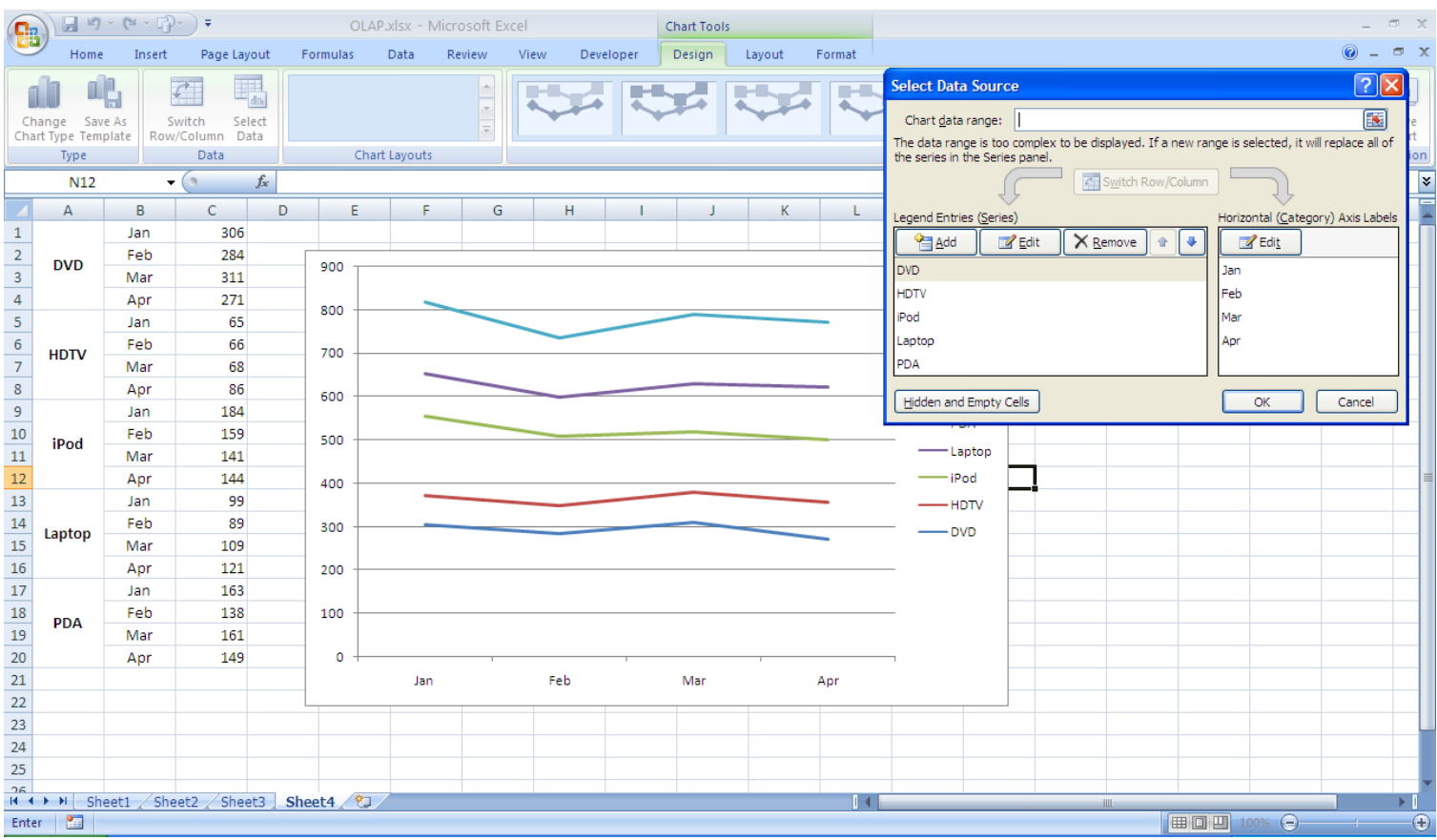

Figure 12. Data Visualization

This section sets three learning goals for students. First, students shall be able to use data visualization methods in Excel for OLAP. Second, students shall understand the types of basic OLAP tasks as articulated in the prototype that can be accomplished by data visualization. Third, students shall be able to extend the OLAP prototype to display various data patterns and comparisons by using a variety of business graphics.

\section{Delivery of the Technical Module}

We have discussed the design of the technical module of OLAP for our BI course. This section describes the delivery of this technical module to our students. Our BI course is an IS elective course offered for all business majors in the school of business at one of the authors' universities. The prerequisite for taking the course is an introductory IS course, which in turn has its two prerequisites of a computer literacy course and a business statistics course. The course includes both non-technical and technical modules. The main topic of the technical module is OLAP. The contact hours for the OLAP part are about one fifth of the course (nine out of forty five contact hours). We have created and used a teaching note to deliver this module that is consistent with the approach described above. Next, we explain the way we used to teach the technical module and the feedback we have received from students. 


\section{Delivery Method: Technical Assignment}

We used a technical assignment for teaching and learning OLAP for the BI course. For students, the assignment was an OLAP competition. The assignment for the OLAP component included six steps, as briefly described below.

Step 1: Preparation - Each student received the teaching note of the technical module along with a small sample data cube resident in a Microsoft Access database file. The data cube consists of sales data and includes the dimensions of branch, product, and time period, as shown in the previous sections of this article. Students were asked to practice the four elemental OLAP techniques as briefly described in the fourth section by following the teaching note.

Step 2: Data acquisition - Each student was asked to use the Northwind Traders database, a companion sample database in Microsoft Access, for this assignment. The Northwind Traders database contains a reasonably large dataset for the assignment and is commonly available. Each student was asked to review all tables and the existing data cubes in the query objects category of the database and to select one or more existing data cubes from the Northwind Traders database for OLAP.

Step 3: OLAP strategy initiation - Each student was asked to act as the new CEO of Northwind Traders, to overview the data set, to understand the nature of the business of this company based on her/his assumptions, and then to generate ideas of OLAP strategy for the company. Each student was asked to articulate her/his OLAP strategy by following the guidelines discussed in the second section.

Step 4: Creating new data cubes - This step was optional, because the Northwind Traders Access database has generated many queries (data cubes) already. However, a student could create new data cubes in Access by using her/his own queries. This optional step encouraged students to develop diverse OLAP strategies.

Step 5: Performing OLAP using Excel - Each student was asked to use Excel to connect the Northwind Traders database, to create OLAP cubes in the form of pivot table in Excel, and to perform OLAP by applying and extending the knowledge and skills acquired through Step 1. Each student was expected to find interesting, meaningful, and significant facts to implement the OLAP strategy, and is encouraged to conduct OLAP by integrating multiple elemental OLAP techniques. The minimum requirements were at least one OLAP result for each of the four elemental OLAP techniques discussed in Section 4, but the quality of OLAP practice was assessed by the competitive comparison of all assignments.

Step 6: Presentation and competition - Each student was required to write a report for the assignment to summarize what she/he had learned from this assignment for OLAP and BI in general, and was required to present the OLAP strategies and findings for a class competition. The best OLAP strategies and the most interesting OLAP results were recognized through class discussions.

\section{Feedback from students}

All students completed the OLAP assignment meeting the requirements specified. Unsurprisingly, the OLAP results were quite diverse since they created their own OLAP strategies. We requested students to anonymously complete a short questionnaire. The responses from 25 students are summarized in Table 1. 


\begin{tabular}{|l|c|}
\hline \multicolumn{2}{|c|}{ Table 1: Summary of Students' Feedback from Sample Classes } \\
\hline \hline & $\begin{array}{c}\text { Percentage of Students } \\
\text { Who Agree } \\
\text { or Strongly Agree }\end{array}$ \\
\hline $\begin{array}{l}\text { 1. The concept of BI empowered by OLAP is important for business } \\
\text { students }\end{array}$ & $88 \%$ \\
\hline $\begin{array}{l}\text { 2. The concept of BI delivered by OLAP meets your expectation of } \\
\text { this course }\end{array}$ & $92 \%$ \\
\hline $\begin{array}{l}\text { 3. You believe that learning OLAP enhances your knowledge set, skill } \\
\text { set, and integrated thinking ability }\end{array}$ & $80 \%$ \\
\hline 4. The OLAP technique is relatively easy to learn & $64 \%$ \\
\hline 5. The workload of the OLAP technical assignment is appropriate & $80 \%$ \\
\hline 6. The OLAP teaching note is useful for the BI course & $88 \%$ \\
\hline
\end{tabular}

We recognize that we have only a small sample, and thus this summary of students' feedback is preliminary. The business intelligence course is still in the trial stage in the IS curriculum and the enrollments of this course have not reached to the normal class size.

\section{Conclusion}

OLAP is an important BI tool, but there has been a lack of hands-on material of OLAP for business students in the existing textbooks and the literature. Through the design and teaching of the OLAP technical module for the BI course, we are convinced that this technical module has positive impacts on learning and teaching BI. Our preliminary observations are encouraging. Student evaluations have indicated their positive learning experiences and overall satisfaction with the OLAP technical module. By exercising the hands-on examples in the teaching note, students had no difficulty in learning the OLAP technical module within a short timeframe. The progressive nature of the technical assignment also accommodates differing levels of preparation for learning the OLAP technique and sets the stage for students to progress to advanced levels on their own. We conclude that the OLAP technical module is practicable and very useful for the BI course.

Our primary purpose writing this article was to share what we have learned and developed while incorporating an OLAP technical module in a non-technical BI class. We have designed and implemented a hands-on OLAP module that operates in the Microsoft Office computational environment, a commonly available platform. The module has identified and provided guidelines for giving instruction on the four elemental OLAP techniques typically applied in performing OLAP-supported analysis. We believe that the OLAP technical module described above helps to fill a gap in non-technical $\mathrm{BI}$ courses where the emphasis has largely been on analyzing business cases. The most compelling implication of this effort is the recognition that BI can be applied virtually everywhere. Our experience demonstrates the potentially positive effect of inclusion of a practical, technical module in BI courses designed to meet the needs of business majors. The above guidelines should be of value to IS instructors wishing to incorporate a practical technical element in their business-oriented BI courses.

\section{Acknowledgement}

The detailed comments of the Editor Dr. John Beachboard have contributed significantly to the revision of the paper. 


\section{References}

Helfert, M. (2008). Business informatics: an engineering perspective on information systems. Journal of Information Technology Education, 7, 223-245.

Houghton, L., \& Ruth, A. (2010). Making information systems less scrugged: Reflecting on the processes of change in teaching and learning. Journal of Information Technology Education: Innovations in Practice, 9 , IIP91-102. Retrieved from http://www.jite.org/documents/Vol9/JITEv9IIPp091-102Houghton799.pdf

Howson, C. (2008). Successful business intelligence. New York, NY: McGraw Hill.

Howson, C. (2012). The business intelligence market. Retrieved May 7, 2013, from http://www.biscorecard.com/folderfd/bimarket.pdf

Hunter, G. (2010). The chief information officer: A review of the role. Journal of Information, Information Technology, and Organizations, 5, 125-143. Retrieved from http://www.informingscience.org/jiito/articles/JIITOv5p125-143Hunter460.pdf

Jafar, M. J. (2010). A tools-based approach to teaching data mining methods. Journal of Information Technology Education: Innovations in Practice, 9, IIP1-29. Retrieved from http://www.jite.org/documents/Vol9/JITEv9IIPp001-024Jafar740.pdf

King, M. A. (2009). A realistic data warehouse project: An integration of Microsoft Access and Microsoft Excel advanced features and skills. Journal of Information Technology Education: Innovations in Practice, 8, IIP91-104. Retrieved from http://www.jite.org/documents/Vol8/JITEv8IIP091-104King696.pdf

Laursen, G. H. N., \& Thorlund, J. (2010). Business analytics for managers: Taking business intelligence beyond reporting. NY: Wiley.

Loshin, D. (2003). Business intelligence: The savvy manager's guide. San Francisco, CA: Elsevier.

Mrdalj, S. (2007). Teaching an applied business intelligence course. Issues in Information Systems, 8(1), 134138.

Negash, S. (2004). Business intelligence. Communications of the Association for Information Systems, 13, 177195.

Olszak, C. M., \& Ziemba, E. (2012). Critical success factors for implementing business intelligence systems in small and medium enterprises on the example of upper Silesia, Poland. Interdisciplinary Journal of Information, Knowledge, and Management, 7, 129-150. Retrieved from http://www.ijikm.org/Volume7/IJIKMv7p129-150Olszak634.pdf

Presthus, W., \& Bygstad, B. (2012). Business intelligence in college: A teaching case with real life puzzles. Journal of Information Technology Education: Innovations in Practice, 11, 121-137. Retrieved from http://www.jite.org/documents/Vol11/JITEv11IIPp121-137Presthus1075.pdf

Raisinghani, M. (2004). Business intelligence in the digital economy. Hershey, PA: The Idea Group.

Shmueli, G., Patel, N. R., \& Bruce, P. C. (2007). Data mining for business intelligence, Hoboken, NJ: Wiley.

Tan, G., \& Venables, A. (2008). Survival mode: The stresses and strains of computing curricula review. Journal of Information Technology Education: Innovations in Practice, 7, IIP 33-43. Retrieved from http://www.jite.org/documents/Vol7/JITEv7IIP033-043Tan429.pdf

Topi, H., Valacich, J. S., Wright, R. T., Kaiser, K., Nunamaker, J. F. Jr., Sipior, J. C., \& de Vreede, G. (2010). IS 2010: Curriculum guidelines for undergraduate degree programs in information systems. Communications of the Association for Information Systems, 26, Article 18.

Turban, E., Sharda, R., Delen, D., \& King, D. (2011). Business intelligence: A managerial approach (2nd ed.). Upper Saddle River, NJ: Pearson Prentice Hall.

Williams, S., \& Williams, N. (2007). The profit impact of business intelligence. San Francisco, CA: Elsevier. 


\section{Biographies}

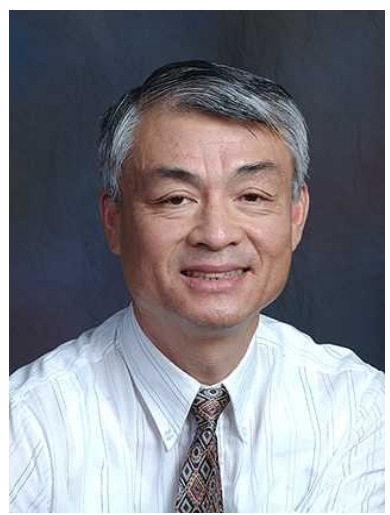

Shouhong Wang is a Professor of Management Information Systems at University of Massachusetts Dartmouth. He received his B.Eng. and M.B.A from Tsinghua University, Beijing, China, and Ph.D. in Information Systems from McMaster University. His teaching and research interests include business intelligence, knowledge management, and design research. He has published several books in MIS and over 100 papers in academic journals, including Journal of Information Technology Education, Journal of Management Information Systems, Information \& Management, IEEE Transactions on Systems, Man, and Cybernetics, Management Science, Decision Sciences, IEEE Transactions on Patter Analysis and Machine Intelligence, Journal of The Operational Research Society, OMEGA, INFORMS Journal on Computing, Information Resources Management Journal, and others.

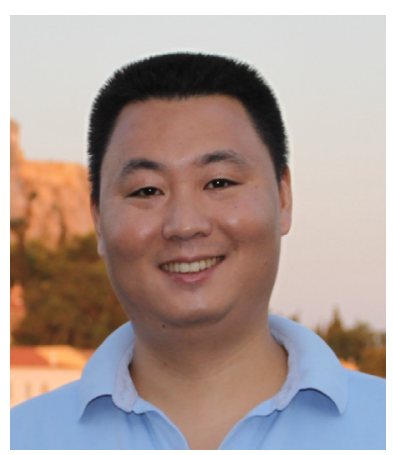

Hai Wang is an Associate Professor at the Sobey School of Business at Saint Mary's University, Canada. He received his B.Sc. from the University of New Brunswick, and his M.Sc. and Ph.D. in Computer Science from the University of Toronto, Canada. His research interests are in the areas of Big Data, data mining, database management, knowledge management, and e-commerce. His papers have been published in Journal of Education for Business, Decision Sciences Journal of Innovative Education, Computer \& Operations Research, IEEE Transactions on Systems, Man, and Cybernetics, Journal of Computer Information Systems, Journal of Database Management, VLDB Journal, and others. 